\title{
An Evidence-Based Alcohol Screening, Brief Intervention and Referral to Treatment (SBIRT) Curriculum for Emergency Department (ED) Providers Improves Skills and Utilization
}

Robert H. Aseltine

University of Connecticut School of Medicine and Dentistry

Amy James

University of Connecticut School of Medicine and Dentistry

Follow this and additional works at: https://opencommons.uconn.edu/uchcres_articles

Part of the Medicine and Health Sciences Commons

\section{Recommended Citation}

Aseltine, Robert H. and James, Amy, "An Evidence-Based Alcohol Screening, Brief Intervention and Referral to Treatment (SBIRT) Curriculum for Emergency Department (ED) Providers Improves Skills and Utilization" (2007). UCHC Articles - Research. 231.

https://opencommons.uconn.edu/uchcres_articles/231 


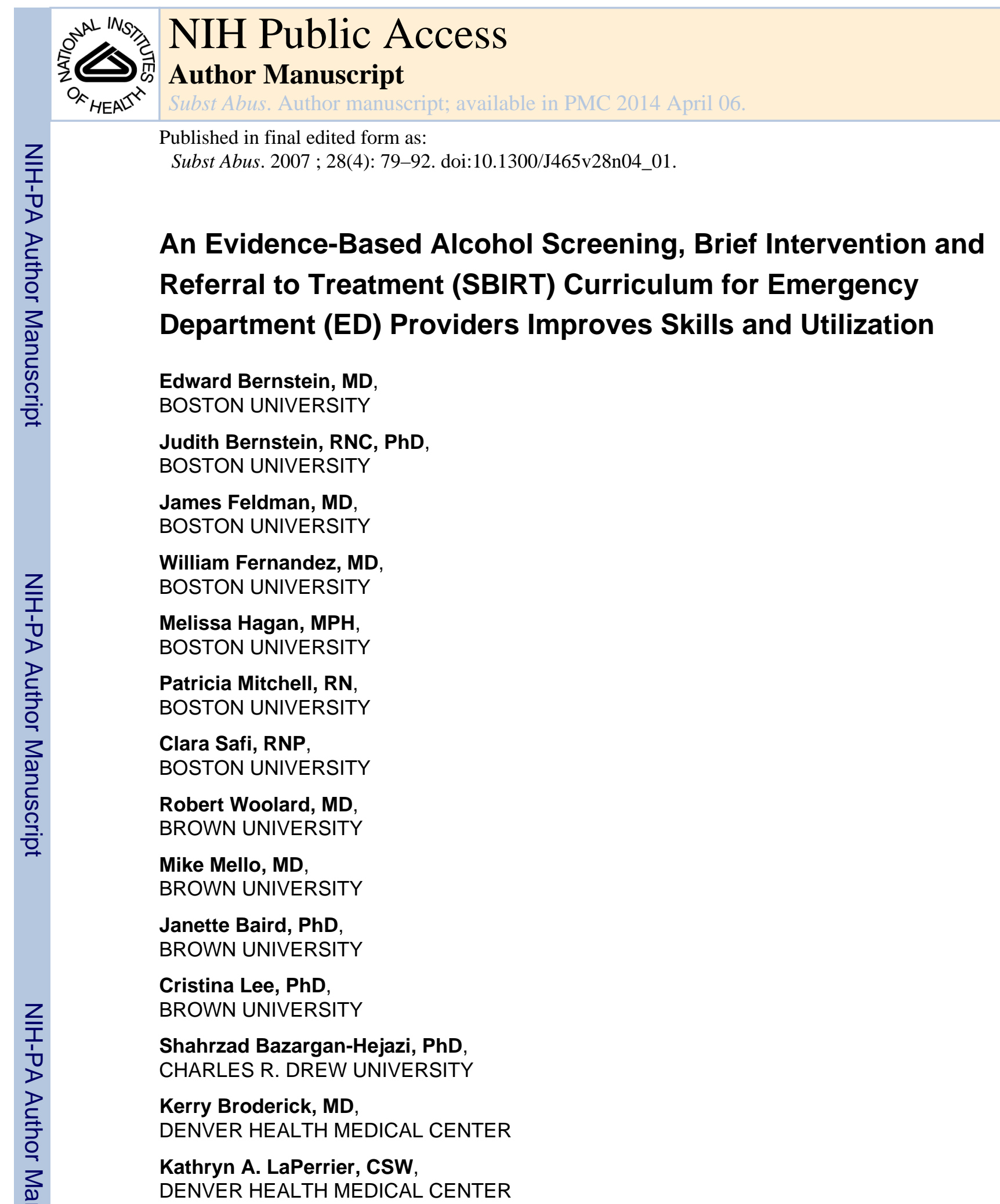

Arthur Kellermann, MD, MPH,

(C) 2007 by The Haworth Press, Inc. All rights reserved.

Address correspondence to: Edward Bernstein, MD, Professor and Vice-Chair for Academic Affairs, Department of Emergency Medicine, Boston University School of Medicine, One Boston Medical Center Place, Boston MA 02118 (ebernste@bu.edu)..

Presented at the Society of Academic Emergency Medicine (SAEM) Annual Meeting, May 2005.

Presented at the Research Society on Alcoholism (RSA) Meeting, June 2005.

There are no financial arrangements that represent conflict of interest. 


\section{EMORY UNIVERSITY}

Marlena M. Wald, MLS, MPH,

EMORY UNIVERSITY

Robert E. Taylor, MD, PhD,

HOWARD UNIVERSITY

Kim Walton, PhD,

HOWARD UNIVERSITY

Michelle Grant-Ervin, MD,

HOWARD UNIVERSITY

Denise Rollinson, MD,

TUFTS UNIVERSITY

David Edwards,

TUFTS UNIVERSITY

Theodore Chan, MD,

UNIVERSITY OF CALIFORNIA, SAN DIEGO

Dan Davis, MD,

UNIVERSITY OF CALIFORNIA, SAN DIEGO

Jean Buchanan Marshall, MS, RN,

UNIVERSITY OF CALIFORNIA, SAN DIEGO

Robert Aseltine Jr., PhD,

UNIVERSITY OF CONNECTICUT HEALTH CENTER

Amy James, PhD,

UNIVERSITY OF CONNECTICUT HEALTH CENTER

Khamis Abu-Hasaballah, PhD,

UNIVERSITY OF MEDICINE AND DENTISTRY OF NEW JERSEY ROBERT WOOD JOHNSON MEDICAL SCHOOL AT CAMDEN

Elizabeth Schilling, PhD,

UNIVERSITY OF MEDICINE AND DENTISTRY OF NEW JERSEY ROBERT WOOD JOHNSON MEDICAL SCHOOL AT CAMDEN

Brigitte M. Baumann, MD,

UNIVERSITY OF MEDICINE AND DENTISTRY OF NEW JERSEY ROBERT WOOD JOHNSON MEDICAL SCHOOL AT CAMDEN

Edwin D. Boudreaux, PhD,

UNIVERSITY OF MEDICINE AND DENTISTRY OF NEW JERSEY ROBERT WOOD JOHNSON MEDICAL SCHOOL AT CAMDEN

Ronald Maio, DO, MS,

UNIVERSITY OF MICHIGAN

Rebecca Cunningham, MD, UNIVERSITY OF MICHIGAN

Teresa Murrell, RN, CCRC, UNIVERSITY OF MICHIGAN

David Doezema, MD,

UNIVERSITY OF NEW MEXICO 
Michael J. Bauer, BA,

UNIVERSITY OF NEW MEXICO

Deirdre Anglin, MD, MPH,

UNIVERSITY OF SOUTHERN CALIFORNIA

Adriana Eliassen, RN, UNIVERSITY OF SOUTHERN CALIFORNIA

Marcus Martin, MD, UNIVERSITY OF VIRGINIA

Jesse Pines, MD, UNIVERSITY OF VIRGINIA

Leslie Buchanan, NP, UNIVERSITY OF VIRGINIA

James Turner, MD, UNIVERSITY OF VIRGINIA

Gail D'Onofrio, MD,

YALE UNIVERSITY

Linda C. Degutis, DrPH, YALE UNIVERSITY

Patricia Owens, MS, and YALE UNIVERSITY

The Academic ED SBIRT Research Collaborative

\section{SUMMARY}

Objective-Emergency Departments (EDs) offer an opportunity to improve the care of patients with at-risk and dependent drinking by teaching staff to screen, perform brief intervention and refer to treatment (SBIRT). We describe here the implementation at 14 Academic EDs of a structured SBIRT curriculum to determine if this learning experience improves provider beliefs and practices.

Methods-ED faculty, residents, nurses, physician extenders, social workers, and Emergency Medical Technicians (EMTs) were surveyed prior to participating in either a two hour interactive workshops with case simulations, or a web-based program (www.ed.bmc.org/sbirt). A pre-post repeated measures design assessed changes in provider beliefs and practices at three and 12 months post-exposure.

Results-Among 402 ED providers, $74 \%$ reported $<10$ hours of prior professional alcoholrelated education and 78\% had $<2$ hours exposure in the previous year. At 3-month follow-up, scores for self-reported confidence in ability, responsibility to intervene, and actual utilization of SBIRT skills all improved significantly over baseline. Gains decreased somewhat at 12 months, but remained above baseline. Length of time in practice was positively associated with SBIRT utilization, controlling for gender, race and type of profession. Persistent barriers included time limitations and lack of referral resources.

Conclusions-ED providers respond favorably to SBIRT. Changes in utilization were substantial at three months post-exposure to a standardized curriculum, but less apparent after 12 months. Booster sessions, trained assistants and infrastructure supports may be needed to sustain changes over the longer term. 


\section{Keywords}

Brief intervention; alcohol screening; substance abuse; alcohol education

\section{INTRODUCTION}

\section{The Rationale for Emergency Department (ED) Screening}

The estimated cost of alcohol abuse and dependence for health care, lost productivity, property damage, criminal justice system involvement and loss of life in the US is in excess of $\$ 185$ billion. ${ }^{1}$ In 2001-2002, the 12 month prevalence for alcohol abuse or dependence was 17.6 million or $8.5 \%$ of the U.S. population, and $29.3 \%$ ofthepopulationexceededrecommended drinking limits. ${ }^{2}$ There were approximately 75,000 alcohol attributable deaths associated with 2.3 million years of potential life lost, ${ }^{3}$ with half of these deaths attributed to binge drinking (consumption of 5 or more drinks for men and 4 or more drinks for women in a 2 hour occasion). ${ }^{4}$ Binge drinking also resulted in 14,600 motor vehiclecrash deaths and increased the risk of injury nine-fold.

Furthermore, out of 110 million ED visits in 2001, 7.6 million were attributable to alcohol. ${ }^{5}$ ED patients are 1.5-3.0 times more likely to reportheavydrinkingorconsequencesthanthose in primary care. ${ }^{6}$ Among ED patients, $31 \%$ screen positive on the CAGE instrument ( $\geq 2$ questions), ${ }^{7}$ more than $10 \%$ of patients meet DSM-

IVorICD-10criteriaforalcoholdependence, ${ }^{8}$ and $25 \%$ are positive on the Alcohol Use Disorders Identification Test (AUDIT) using a probability sample. ${ }^{9}$ In a five year follow-up, alcohol intoxicated ED patients had twice the mortality rate as the non-intoxicated comparison group. ${ }^{10}$

Currentrates of screening in the ED are in adequate to identify and address alcohol problems, and alcohol on breath is insufficient as a diagnostic procedure. ${ }^{7}$ If $10 \%$ of ED patients meet criteria for dependence and another $20 \%$ meet criteria for possible dependence with CAGE >2, then one might estimate conservatively that at least 10 million ED visits in any given year should be associated with a referral for assessment and/or treatment contact, and manymillionsofhighriskdrinkers, whoarenot dependent but simply drinking at levels that have negative health effects, would benefit from briefintervention.In 2001, however, only $11.4 \%$ of the 2.5 million patients whose visit was directly related to alcohol use (those with analcoholattributablemedicalcondition)were referred for treatment. ${ }^{11,12}$ These findings provide compelling clinical and public health reasons for the ED to institute systems for alcohol screening, brief intervention and referral to treatment (SBIRT) in order to improve the care of patients with high risk or dependent drinking.

\section{The Potential for Brief Intervention in the ED}

SBIRT has been tested for over 20 years in primary care/general medicine settings. A systematic review of randomized controlled trials by the US Preventive Service Task Force found that at least one 15 minute conversation by a primary care provider resulted in 2.9-8.7 fewer mean drinks per week (13\%-34\% net reduction) and a 10\%-19\% increase in the number of persons drinking at moderate to safe levels, compared to control groups. ${ }^{13}$ Some early ED studies support this use of brief intervention to reduce high risk drinking and associated consequences. For example, in a trial of a 40 minute motivational intervention plus follow-up booster by non ED providers, investigators at Brown Medical School reported that sub-critically injured drinking patients in the intervention group had fewer alcohol-related injuries and consequences than controls at 12 month follow-up. In the 
subgroup of patients presenting as a result of motor vehicle crashes, the intervention group had $1 / 3$ fewer alcohol related injuries than controls. ${ }^{14,15}$

In a systematic review of four ED based studies of brief intervention, D'Onofrio and Degutis conclude that ED intervention is effective, and recommend that ED screening and brief intervention be incorporated into clinical practice. ${ }^{16}$ While it is not yet clear which subgroups of ED patients are most likely to benefit, ${ }^{17}$ there is clearly a need to evaluate SBIRT in the ED setting. Here we report results from the implementation of a standardized SBIRT curriculum for ED providers that was designed as part of a 14 site trial of SBIRT with ED patients who screen positive for high risk or dependent drinking.

\section{Implementation of a Standardized Curriculum in a Single ED Site}

In 1998, D'Onofrio et al. conducted a small controlled trial of a structured educational intervention for ED residents $(n=36)$ at two sites using a pre-post survey, and demonstrated improvement in knowledge scores and increase in documentation of screening and intervention from $17 \%$ to $58 \%$ on the medical charts reviewed. ${ }^{18}$ Building on this earlier work, D'Onofrio and colleagues at Yale then developed and successfully implemented an innovative skills-based educational program for a variety of emergency practitioners. ${ }^{19} \mathrm{ED}$ faculty, residents and physicians' assistants demonstrated their proficiency in a brief negotiation interview, the BNI, using standardized patient scenarios. During the 2002-2003 study period, 47 ED providers performed a total of 247 interventions with a mean duration time of 7.75 minutes. This study demonstrated the need to test a standardized curriculum with a wider population of ED practitioners, and set the stage for a multi-centered trial of a standardized SBIRT curriculum.

\section{Translation to Academic EDs Across the Nation}

In March 2003, the Society for Academic Emergency Medicine (SAEM) and the National Institute on Alcohol Abuse and Alcoholism (NIAAA) invited the National Alcohol Screening Day (NASD) working group to help develop a translational research study to determine whether ED providers can implement SBIRT under real-time ED conditions and link provider performance to improvements in ED patient outcomes.

Academic Emergency Departments were selected as a focus for this dissemination effort because this setting offered a conjunction of need (high problem prevalence but no alcohol content in the ED training curriculum other than acute clinical care) and opportunity (the availability of an existing structure of weekly conferences for resident education). This familiar venue was critical to acceptance of SBIRT training, because (1) physicians and nurses were being asked to step outside their content comfort zone of pathophysiology of alcohol to focus on communication skills for behavior change, an area of less expertise, and (2) to step outside the ED paradigm of crisis care to learn skills aimed at prevention (for the high risk drinker) or treatment of chronic conditions (for the dependent drinker). Because didactic approaches to altering medical practice have not proved to be very successful, ${ }^{19}$ we selected a more effective strategy of interactive, skills-based format. ${ }^{20}$

Syllabi and educational materials developed for the primary care setting are not readily accepted by emergency physicians, because the conditions of practice-acuity, time constraints, patient management by a multidisciplinary team, delegation of duties, planned discontinuity of care, legally mandated, uncontrolled access, and crisis-oriented scope of mission-are so different from those that obtain in the usual physician-patient relationship. A psychiatrist might define brief intervention as 10 sessions, a primary care provider might define it as three short visits, but for the ED staff, the window of opportunity for brief intervention might be only 10 minutes, with the baton then passed to someone else. We 
describe here the evidence-based SBIRT curriculum that was therefore designed specifically for ED providers, its implementation at 14 academic ED sites, and its impact on the practices and beliefs of ED physicians, nurses (RNs), nurse practitioners (NPs), physicians' assistants (PAs), social workers and Emergency Medical Technicians (EMTs).

\section{METHODS}

\section{Study Design}

This trial of an educational intervention was embedded within a controlled comparison of the effect of SBIRT on ED patient outcomes at 14 sites. Institutional Review Board approval for the provider component was obtained at each of the fourteen sites, and a the Alcohol Education Project parent site at Boston University, and written informed consent was obtained from all participating providers. A pre-post-retention repeated measures design was used to test the hypothesis that ED providers from a variety of disciplines would change their beliefs and practices at 3 and 12 months post exposure to a standardized SBIRT curriculum. In Phase I, the control period in Spring, 2004, 40 ED patients at each site who screened positive for high risk or dependent drinking were enrolled by a study coordinator or designated research assistant. In Phase II, ED providers enrolled in the study, completed a pretest about alcohol beliefs and professional experiences and practices, and were exposed to the SBIRT curriculum via local workshop or via web-based learning module. In Phase III (Late Spring and Early Summer, 2004), the enrolled ED providers had the opportunity to participate in a trial of screening, brief intervention and referral of ED patients at each site during their clinical shifts. In Phase IV, ED providers completed a post-test at 3 months and 12 months.

\section{Sample}

During the spring of 2004, each of the 14 sites issued an invitation to ED faculty, residents, nurses, nurse practitioners, physician's assistants, social workers, EMTs and other ED based staff to enroll in the study.

\section{Setting}

The 14 academic ED sites participating in the study were affiliated with the following institutions: Boston University, Brown University, Charles R. Drew University, Denver Health Medical Center, Emory University, Howard University, Tufts University, University of California San Diego, University of Medicine and Dentistry of New Jersey, University of Michigan, University of New Mexico, University of Southern California (LAC), University of Virginia and Yale University. These urban and suburban teaching hospitals with ED residencyprograms, whorepresentedallregionsof the country and served a large, diverse patient population, each received an RO3 from NIAAA to fund their participation in the study.

\section{Curriculum Components}

The curriculum consisted of: (1) a 30 minute slide show on the rationale for and research supporting SBIRT effectiveness; (2) a series of five video cases in which ED providers demonstrate intervention skills and the BNI algorithm with simulated patients; (3) scripted scenarios for practicing skills; (4) pocket sized plastic cards with NIAAA screening guidelines, a graphic display of typical drinks and the intervention algorithm; and (5) a web site designed for independent learning (www.ed.bmc.org/sbirt).

A research team and an educational coordinator at each site facilitated all aspects of the program including assisting practitioners with independent learning. Boston University and 
Yale University provided technical assistance, curriculum development and instructors for local workshops at each site.

\section{Curriculum Content}

The Two Minute Screen-The screening protocol consisted of three questions prefaced by the statement, "I ask all my patients these questions in order to give better care. Would you mind answering them?"

- On average, how many days per week do you drink alcohol (beer, wine, liquor)?

- On a typical day when you drink, how many drinks do you have?

- What is the maximum number of drinks you had on any given occasion during the last month?

A standard drink is defined as 12 ounces of beer, 6 ounces of wine or 1.5 ounces of liquor. National Institute of Alcohol Abuse and Alcoholism epidemiologically based guidelines for low risk consumption ${ }^{22}$ were taught to providers. According to these guidelines, drinking at the following levels puts patients at risk for injury or illness and constitutes a positive screen:

- $\quad>14$ drinks/week for men

- $\quad>7$ drinks/week for women

- $\quad>1$ drink per day for those 65 years or older

- $\quad>0$ drinks during pregnancy and for those dependent on alcohol or on medications that interact with alcohol

- $\quad>4$ drinks for men and $>3$ drinks for women per 2 hour drinking occasion

Development of the BNI Intervention-The intervention, a discussion designed to be completed in 5-10 minutes, is built on best practices derived from the literature. ${ }^{23-27}$ The goal of the brief intervention curriculum was to offer ED providers an array of skills/tools that can be adapted to any particular situation they encounter in interacting with patients with high risk or dependent drinking, since resistance to discussion of behavior change is normally expected. The BNI was designed to be efficient, effective, respectful, and satisfying to both patient and practitioner, and give patients a voice and a choice. The original version was developed in 1994 for Project ASSERT at the Boston Medical Center ED with the help of Dr. Stephen Rollnick, ${ }^{28}$ and is illustrated in the video, "The Emergency Physician and the Problem Drinker." ${ }^{29}$ D'Onofrio, Pantalon et al. further adapted and standardized the intervention as an algorithm for Project ED Health, 2001. ${ }^{19}$ These two versions were merged for the current study.

Key Elements of the BNI-After asking permission to raise the subject, the ED provider reviews screening results in light of the NIAAA guidelines for low risk drinking, and assists the patient to make a connection between alcohol use and the reason for visit or stated health concerns (Figure 1). The provider thenworks with thepatientto enhance motivation, developing discrepancies between the benefits and losses that the patient associates with drinking and between the patient's current life situation and his/her future goals. The patient's natural resistance to change can be mitigated by avoiding judgmental labeling and finger pointing, through reflective listening based on empathy and respect, and by building on previous attempts at change. The readiness ruler with which a patient identifies his or her level of readiness to change (on a scale of 1 to 10) offers a technique to help patients to voice their own concerns. The provider's question "why not a lower number" may elicit change talk such as, "I crashed my car tonight, cut up my face and spent six hours in the ER 
getting sutured and X-rayed, so I've got to slow down a bit.” The provider reinforces positive commitment statements, because the number of such statements and their salience is associated with positive change and better outcomes. ${ }^{30}$ The next step is to negotiate a specific action plan (prescription for change) with the patient to reduce risks and consequences related to drinking. The semi-structured format is the method cited as most closely associated with better effect size and outcomes. ${ }^{31}$

Referral Resources-Each site was assisted to develop a resource/referral list and to work closely with social workers, addiction counselors, and Alcoholics Anonymous volunteers, and to use the Center for Substance Abuse Treatment's Treatment finder web site. ${ }^{32}$ Patients are encouraged to take responsibility for lifestyle change, explore personal and community resources for change, and make decisions that they think they can actually carry out.

Measurement-An ED Clinician Survey adapted from D'Onofrio et al. ${ }^{18}$ was administered prior to SBIRT exposure and at 3 and 12 months post training. The survey includes demographics, prior exposure to an alcohol curriculum, beliefs about alcohol and about intervention, and an inventory of current practices with patients who are high risk or dependent drinkers. Likert-format survey responses (scale:1-5) at baseline and at follow-up were compared for changes in the following domains: (1) perceived ability to conduct SBIRT skills, (2) responsibility to conduct SBIRT, (3) perceived barriers, and (4) self reported utilization of SBIRT skills. Composite mean scores were calculated from the responses to the screening, brief intervention and referral questions within each domain. For example, in the utilization domain, the following questions were asked [never to always]:

- How often do you ask patients about their alcohol problems?

- How often do you ask about quantity and frequency of use?

- How often do you formally screen patients using CAGE?

- How often do you assess patients' readiness to change?

- How often do you discuss/advise patients to change their drinking behavior?

- How often do you refer patients with alcohol problems?

- How often do you document your assessment, intervention and referral?

For responsibility, the question was phrased as, "What do you think is your responsibility as an emergency physician, nurse or physicians' assistantto do the following [same items, no responsibility to major responsibility]?" For confidence, the questions were phrased as "Rate the following statements according to your confidence/ability level [from no confidence to high confidence]. I am confident in my ability to ... [same items]."

Data Analysis-Chi-square analysis was used for bivariate comparison of nominal data. Paired $t$ tests were performed for pre-post comparison of composite mean scores, and an OLS regression model was developed for analysis of independent predictors. SPSS ${ }^{\circledR}$ software was used for analysis.

\section{RESULTS}

\section{Participants}

The 402 ED providers were enrolled; $83 \%(\mathrm{n}=334)$ were reassessed at 3 months, and $72 \%$ $(\mathrm{n}=288)$ were reassessed at 12 months. 


\section{Baseline Survey}

Participants were 52\% male, and diverse in their disciplines (60\% MDs, $21 \%$ RNs, $7 \%$ RNP or PAs, and $8 \%$ social workers and 3\% EMTs). Among the physicians, $31 \%$ were residents, and there was variation of length of time in practice from 1-5 years (14\%) to 6-10 years $(16 \%)$ to $10+$ years $(38 \%)$. The majority $(74 \%)$ attended workshops; the remainder used the website for independent learning or small group sessions.

Previous alcohol related training and experience-While $68 \%$ rated their past experience working with patients with alcohol problems as 'moderate' or 'large,' $74 \%$ reported having less than 10 hours of alcohol education during graduate or post-graduate training, and $78 \%$ reported less than 2 hours of alcohol education in the previous year.

\section{Pre-Post Comparisons at 3 Months}

Providers who completed the three month follow-up survey were not different in demographics, alcohol experience or training or alcohol beliefs from those who were lost to follow-up. Paired samples $t$-tests demonstrated improvement post-exposure to the SBIRT curriculum in all four domains (see Table 1).

Skills and responsibility at 3 months-Confidence in ability to perform SBIRT skills improved by $11 \%$, and perception of responsibility to provide SBIRT increased by $7 \%$.

Barriers to SBIRT utilization at $\mathbf{3}$ months-Items assessed included lack of time, lack of referral resources, legal issues about documentation, lack of role models among faculty for screening, potential for angry response from patients, and lack of belief in effectiveness of treatment. At post-test, barriers were rated as less troublesome but by a decrease of only $3 \%$. Overall, providers indicated a greater belief that SBIRT would make a difference (mean score 3.65 at baseline vs. 3.93 at 3 months, a difference of 0.28 ( $<<.001,95 \%$ CI -.37, - . 17). Both time required for an intervention and lack of referral resources remained serious concerns (see Figure 2).

Changes in SBIRT utilization at 3 months-Two hundred and twenty-seven providers (72\%) reported that they conducted at least one intervention as part of the study. Providers were $30 \%$ more likely to use SBIRT than they had been at baseline. The effect of training on utilization was rated 7.8 for the workshop and 7.2 for the web on a scale of 1-10.

Predictors of utilization at $\mathbf{3}$ months-We used linear regression to identify predictors of increased SBIRT utilization, entering gender, profession, years in practice, and race and ethnicity, controlling for pre-test scores (see Figure 3). As years in practice increased, likelihood of SBIRT utilization increased (beta $.015, \mathrm{p}<.001,95 \%$ CI $.008, .021$ adjusted $\mathrm{R}^{2} .309$ ). Demographics and type of profession (i.e., MD vs. RN vs. EMT) were not significant predictors of utilization.

\section{Pre-Post Comparisons at 12 Months}

Paired samples $t$-tests demonstrated sustained improvement over baseline in all domains except barriers (see Table 1). Enrollees who were followed were not significantly different in demographics or baseline composite scores from those lost to follow-up, but resi dents were less likely to be followed because many completed their training and moved away during the follow-up year.

Skills and responsibility at $\mathbf{1 2}$ months-Confidence in ability to perform SBIRT remained at $8 \%$ over baseline, but there was a $2 \%$ drop-off from the score at 3 months. 
Perception of responsibility to provide SBIRT held at 5\% over baseline, but again dropped $2 \%$ from the 3 month score.

Barriers at 12 months-At post-test, barriers were not significantly different than at 3 months. Providers indicated continued belief that SBIRT would make a difference (3.74, $\mathrm{p}$ $<.001,95 \% \mathrm{CI}-.26,-.01)$, a $3 \%$ increase over baseline but a $5 \%$ decline from the 3 month score.

SBIRT utilization at $\mathbf{1 2}$ months-Providers were $11 \%$ more likely to use SBIRT than at baseline, but there was a drop-off of $15 \%$ from the 3 month score.

\section{Provider Comments}

Successful experiences

\section{(3 months post-training)}

- I am shocked-patients are willing, and concerned about their ETOH problems. Because of my intervention with them I have had a very different rapport with my patients. We worked together. Again, I am amazed by the outcome.

- It takes a significant time commitment but it is important and worth while.

\section{(12 months post-training)}

- Patients seen much more responsive when using SBIRT. I found it surprisingly rewarding and patients were very receptive.

- So far, more patients than not have agreed to making some changes in their behavior.

- Often surprised how willing people are to agree to change and sign a contract to that effect.

- Patients are mostly very receptive to non-judgmental intervention.

- Patients seem responsive to counseling, especially if you show interest in the patient. Several patients have returned and mentioned that the interview was helpful.

\section{Barriers}

- There is too much pressure from both attending MDs and Nurse Management to "move" and keep the patient "thru put" flowing for any of the nursing staff to perform an effective job in the alcohol screening. If we did do it correctly there would be criticism for not keeping up with the other patient acuity and overloading issues.

- I have had patients who are ready to change and sober and I cannot find a detox bed and at time of discharge from ER I send them with all the phone numbers and maybe a prescription for Ativan (if the MD will give one) and I feel as if I have failed them. It is like losing the one teachable moment.

\section{Differences Among Sites}

Among the 14 sites, three had pre-existing project ASSERT-type programs in which there were peer educators or trained extenders available in the ED to assist with referrals. At baseline, providers at these sites reported significantly higher means for ability ( 3.13 vs. 2.97, a difference of $0.16, \mathrm{p}<.05,95 \%$ CI .01, .31) and utilization (3.90 vs. 3.70, a 
difference of $0.20, \mathrm{p}<.05,95 \% \mathrm{CI} .01, .39)$. While there were no differences in ability or utilization identified at follow-up, providers at the ASSERT sites were more likely to refer at 3 months (mean score 3.78 vs. 3.26, a difference of 0.52 , p < .001, 95\% CI $-.78,-.26$ ).

\section{Comparison with Score Reported from the D'Onofrio et al. Controlled Trial, 2002}

Mean composite scores were converted for comparability from a Likert scale of 1 to 5 to the 100 point scale reported in the previous study. ${ }^{18}$ Baseline scores were somewhat higher in the present study, but improvements were comparable, and there was no significant difference in the percentages of pre-post improvement achieved in the two studies (Table 2).

\section{DISCUSSION}

ED providers at 14 academic sites across the country reported positive changes in their beliefs and clinical practices in response to exposure to a standardized SBIRT curriculum at 3 and 12 months. These findings involving 402 providers were very similar to previous findings by D'Onofrio et al. at one site. As reported in the survey results, these providers responded positively to SBIRT training, but recognized a need for institutional support and continued supervised clinical practice of SBIRT, and found that time constraints, reimbursement problems and lack of referral resources require major system changes. These barriers may explain why we observed only modest impact of the curriculum with attenuation evident at 12 months.

Nevertheless, there are many reasons for optimism. Thirty years ago internists did not recognize the importance of lipid screening and addressing diet and exercise behaviors. Today screening and recommendations for lifestyle behavior change are a standard of care. Emergency nursing and physician's professional organizations have supported National Alcohol Screening Day since 2000, and have endorsed policies to promote ED SBIRT. When this study was first announced in April 2003, Dr. Ting Kai Li, NIAAA Director, asserted that "Hospital EDs offer a unique opportunity not available elsewhere for alcohol abuse screening, brief counseling, and referral." Charles Curie, speaking for the Substance Abuse and Mental Health Administration (SAMHSA), added that "These efforts can reorient many people away from behaviors that, unchecked, can lead to addiction. For example, screening and refer ral to appropriate services for people who were driving while intoxicated could prevent repeat traumas and save countless lives." 33

In this study, recognized ED leaders championed SBIRT nationally and in their own institutions. Also encouraging is the fact that ED providers who reported limited exposureto SBIRT in their ED training learned to go beyond the "found down" and "alcohol on breath" screening test to adopt a more standardized approach. The millions of ED patients with high risk and dependent drinking and those patients with frequent visits contribute to the high morbidity, mortality and costs and will continue to have a significant impact on the already stressed ED. Practical strategies to maximize efficient, effective approaches and to enhance patient and staff satisfaction were welcomed by providers, and this before and after study found that a relatively brief educational intervention was associated with small changes in confidence, responsibility and use of SBIRT by ED providers. It seems that more work is warranted to achieve greater changes in practices.

This evaluation of the impact of a standardized curriculum for providers was the companion pieceto a trialof SBIRT among ED patients at these 14 sites. In this study, 2,051 ED patients ( $26 \%$ of those screened) exceeded the low-risk limits set by NIAAA; 1,132 consented and were enrolled (581 control, 551 intervention). At three month follow-up, patients receiving brief intervention by providers trained in the standardized curriculum reported significantly lower numbers of drinks per week (3.25) than controls, and were twice as likely as controls 
to be drinking under the NIAAA low-risk limit. This study demonstrated that an intervention by ED providers has some potential to reduce the alcohol consumption of ED patients and make an impact on alcohol-related morbidity, mortality and cost. ${ }^{34}$

Overall the educational effort was well received, and the learning curve was rapid. The curriculum offered an opportunity for ED residents to practice the Accreditation Council for Graduate Medical Education general core competencies for communication with patients, which state that ED professionals are expected to communicate effectively, demonstrate caring and respectful behaviors when interacting with patients and their families, counsel and educate patients and their families, and use effective listening skills. ${ }^{35,36}$

The concept of screening for alcohol use disorders or high risk drinking was easily accepted by ED practitioners, but universal screening takestime, and many drinkers are missed by targeted screening based on risk categories. NIAAA now recommends a single question that might be easily asked at triage:"How many times in the last month have you had 4 or more drinks on one occasion (for a female, or 5 or more for a male)?"

The intervention algorithm also contained many familiar elements taught as part of the medical interview. Patients were given feedback on the results of testing, the readiness ruler resembled pain scales commonly used in the ED, and patients received advice on how to avoid health consequences. The impact of the BNI on behavioral change is based on the fact that"the way clients are spoken to about changing addictive behavior affects their willingness to talk freely about why and how they might change." ${ }^{37}$ Although professional feedback and advice and the teachable moment of an ED visit/personal crisis are powerful external motivators, they are not sufficient. Provider skills are necessary to facilitate and enhance internal motivation to change. Change is more likely, if patients can be assisted to name the problem and solution for themselves and come up with a workable/efficacious plan that specifies concrete steps for addressing high risk and dependent drinking. In a number of cases referral will be needed, and ED providers will be more likely to refer if physician extenders, either peer counselors or social workers) are available to take the time that is required to ensure a successful placement for substance abuse. ${ }^{38}$

Furthermore, evidence has accumulated that patients exposed to SBIRT benefit from a booster session. ${ }^{14}$ This study did not include any reinforcement after the formal training was concluded, and we should not be surprised by the drop-off in utilization at 12 months in the absence of a booster.

\section{LIMITATIONS}

Time available for the education program and intervention practice was limited by real-life conditions; SBIRT was one of many issues competing for the attention of residents. Changes observed in means were small, but still significant in a real-world setting. Because this study was intended as translational research, there was variation in practice from site to site, but training effects were still consistent across sites. Some residents were unavoidably lost to follow-up as they moved to take up new positions, but the follow-up rate was substantial at both three and 12 months, and those lost to follow-up were not different at baseline in prior training, demographics, confidence in ability or utilization of SBIRT. We would have liked to be able to evaluate the impact of independent study using the website, but our counter system did not allow us to link website users to study numbers. Some participants used the website in lieu of the workshop, while others used it as a booster, but we had no way to distinguish between these different modes. And of course, in a pre-post design without a control group, differences in outcomes may be confounded by secular trends or social desirability bias. 


\section{CONCLUSIONS}

Exposure to an interactive screening, brief intervention and referral to treatment curriculum may increase competency and responsibility, decrease perceived barriers, and increase the likelihood of utilizing SBIRT. Training effects observed at three months persisted but were not sustained at the same level at 12 months. Resources such as computerized screening and the addition of ancillary support personnel to the ED team might increase the likelihood of SBIRT utilization. A booster workshop at six months might assist in sustaining changes in utilization.

\section{Acknowledgments}

Funded in part by NIAAA 1R25AA014957, 1R03AA01511-14.

\section{REFERENCES}

1. Harwood, HJ. Updating estimates of economic costs of alcohol abuse in the United States: estimates, update methods, and data. National Institute of Alcohol Abuse and Alcoholism; Bethesda, MD: 2000.

2. Grant BF, Dawson DA, Stinson FS, Chou SP, Dufour MC, Pickering RP. The 12-month prevalence and trend in DSM-IV alcohol abuse and dependence, 1991-1992 and 2001-2002. Drug Alcohol Depend. 2004; 74:223-234. [PubMed: 15194200]

3. Center for Disease Control. Alcohol-attributable deaths and years of potential life lost-United States 2001, MMWR Morb Mort Wkly Rep. 2004; 53:866-870.

4. Brewer RD, Swahn MH. Binge drinking and violence. JAMA. 2005; 294:616-617. [PubMed: 16077057]

5. McDonald AJ III, Wang N, Camargo CA Jr. US emergency department visits for alcohol-related diseases and injuries between 1992 and 2000. Arch Intern Med 2004. 164:531-537.

6. Cherpitel CJ. Drinking patterns and problems: a comparison of primary care with the emergency room. Subst Abus. 1999; 20:85-95. [PubMed: 12511823]

7. Bernstein E, Tracey A, Bernstein J, Williams C. Emergency Department detection and referral rates for patients with problem drinking. Subst Abuse. 1996; 17:69-76.

8. Lowenstein SR, et al. Behavioral risk factors in Emergency Department Patients: A multi-site survey. Acad Emerg Med. 1998; 5:781-787. [PubMed: 9715239]

9. Cherpitel CJ. Screening for alcohol problems in the emergency department. Ann Emerg Med. 1995; 26:158-166. [PubMed: 7618778]

10. Davidson P, Koziol-McLain J, Harrison L, Timken D, Lowenstein S. Intoxicated ED patients: A five year follow-up of morbidity and mortality. Ann Emerg Med. 1997; 30:593-597. [PubMed: 9360567]

11. McCaig, L.; Burt, CW. Advance data from vital and health statistics, no. 335. National Center for Health Statistics; Hyattsville, MD: 2003. National Hospital Ambulatory Medical Care Survey. 2001emergency department summary..

12. [10/9/05] Results from the 2003 National Survey on Drug Use and Health: National Findings. Office of Applied Studies, Substance Abuse and Mental Health Services Administration. Available at: www.oas.samhsa.gov/nhsda/2k3nsduh/2k3Results.htm

13. Whitlock EPM, Polen MRM, Green CAP, Orleans TP, Klein JM. Behavioral counseling interventions in primary care to reduce risky/harmful alcohol use by adults: a summary of the evidence for the U.S. Preventive Service Task Force. Ann Intern Med. 2004; 140:557-568.

14. Mello MJ, Nirenberg TD, Longabaugh R, Woolard R, Minugh A, Becker B, et al. Emergency department brief motivational interventions for alcohol with motor vehicle crash patients. Ann Emerg Med. 2005; 45:620-625. [PubMed: 15940095]

15. Longabaugh R, Woolard RE, Nirenbereg TD. Evaluating the effects of a brief motivational intervention for injured drinkers in the emergency department. J Stud Alcohol. 2001; 62:806-816. [PubMed: 11838918] 
16. D'Onofrio GD, Degutis LC. Preventive care in the emergency department: screening and brief intervention for alcohol problems in the emergency department: a systematic review. Acad Emerg Med. 2002; 9:627-638. [PubMed: 12045080]

17. D'Onofrio G, Degutis LC, Fiellin DA, Pantalon MV, Busch SH, Chawarski MC, O'Connor PG. Emergency practitioner-performed brief interventions for harmful and hazardous drinkers in the emergency department. Acad Emerg Med. 2002; 12(suppl 1):59-60.

18. D'Onofrio G, Nadel ED, Degutis LC, Sullivan LM, Casper K, Bernstein E, Samet J. Improving emergency medicine residents' approach to patients with alcohol problems: A controlled educational trial. Ann Emerg Med. 2002; 40:50-62. [PubMed: 12085073]

19. D'Onofrio GD, Pantalon MV, Degutis LC, Feillin DA, O'Connor PG. Development and implementation of an emergency department practitioner-performed brief intervention for hazardous and harmful drinkers in the emergency department. Acad Emerg Med. 2005; 12:211218. [PubMed: 15741583]

20. Davis DA, Thompson MA, Oxman ED, et al. Changing physician performance: A systematic review of the effect of medical education strategies. JAMA. 1995; 274:700-705. [PubMed: 7650822]

21. Saitz R, Sullivan LM, Samet JH. Training community-based clinicians in screening and brief intervention for substance abuse problems: Translating evidence into practice. Substance Abuse. 2000; 21:21-31. [PubMed: 12466645]

22. The Physician Guide to Helping Patients with Alcohol Problems. National Institute of Alcohol Abuse and Alcoholism (NIAAA); U.S. Government Printing Office; Rockville, MD: 2004. NIH Publication no. 4-3769

23. Chafetz ME, et al. Establishing treatment relations with alcoholics. J Nerv Ment Dis. 1962; 134:395-409. [PubMed: 13877834]

24. Miller, WR., editor. Enhancing motivation for change in substance abuse, Treatment Improvement Protocol Series \#35. US DHHS; Rockville, MD: 1999.

25. Miller, WR.; Rollnick, S. Motivational Interviewing: Preparing People to Change Addictive Behaviors. Guilford; New York: 2002.

26. Prochaska, JO.; DiClemente, C. Stages of change in the modification of problem behavior. In: Hersen, M.; Eisler, R.; Miller, P., editors. Progress in behavior modification. Sage; Newbury Park, CA: 1992.

27. World Health Organization Brief Intervention Study Group. A cross national trial of brief interventions with heavy drinkers. Am J Pub Health. 1996; 86:948-955. [PubMed: 8669518]

28. Bernstein E, Bernstein J, Levenson S. Project ASSERT: An ED-based intervention to increase access to primary care, preventive services, and the substance abuse treatment system. Ann Emerg Med. 1997; 30:181-189. [PubMed: 9250643]

29. D'Onofrio, G.; Bernstein, E.; Bernstein, J. The Emergency Physician and the problem drinker. Marino Productions; Boston: 1998.

30. Amrhein PC, Miller WR, Yahne CE, Palmer M, Fulcher L. Client commitment language during motivational interviewing predicts drug use outcomes. J Consult Clin Psychol. 2003; 71:862-878. [PubMed: 14516235]

31. Hettema J, Steele J, Miller WP. A meta-analysis of research on motivational interviewing treatment effectiveness. Ann Rev Clin Psych. 2005; 1:91-111.

32. SAMHSA. Substance Abuse Facility Locator. Available at: http://dasis3.samhsa.gov/ Accessibility verified August 17, 2005

33. NIH News Alcohol Agencies Announce Academic Emergency Medicine Department Collaboration. http://www.niaaa.nih.gov/press/2004/NASD04-04.htm

34. Academic ED SBIRT Collaborative. The impact of screening, brief intervention and referral to treatment of emergency department patients' alcohol use. Ann Emerg Med. Sep 15.2007 Epub ahead of print.

35. ACGME Outcome Project.. Accreditation Council for Graduate Medical Education. Available at http://www.acgme.org Accessibility verified August 17, 2005

36. Hobgood CD, Riviello RJ, Jouriles N, Hamilton G. Assessment of communication and interpersonal skills competencies. Acad Emerg Med. 2002; 9:1257-1269. [PubMed: 12414480] 
37. Rollnick S. Comments on Dunn et al.'s "The use of brief interventions adapted from motivational interviewing across behavioral domains: a systematic review." Enthusiasm, quick fixes and premature controlled trials. Addiction. 2001; 96:1769-1770. [PubMed: 11784469]

38. Bernstein E, Bernstein J. Commentary- SBIRT: Qualified trained assistants are necessary but not sufficient. Acad Emerg Med. 2005; 12:786-787. [PubMed: 16079435] 


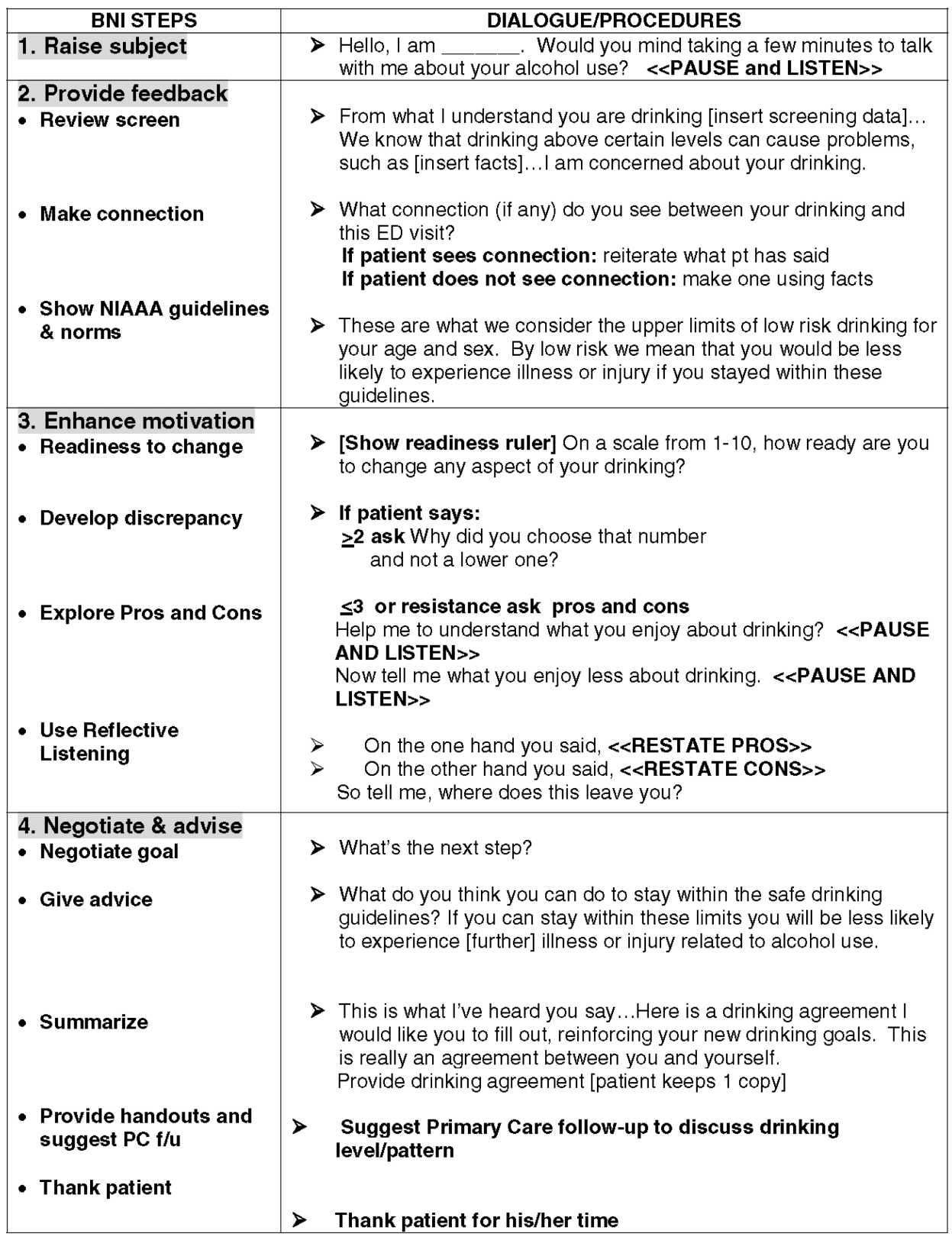

ED=Emergency Department; BNI=Brief Negotiated Interview; SBIRT=Screening, Brief Intervention and Referral to Treatment; $\mathrm{PC}=$ Primary care; NIAAA=National Institute of Alcohol Abuse and Alcoholism Adapted from 19,28,29

FIGURE 1.

SBIRT Algorithm as Taught in the Standardized ED Curriculum 


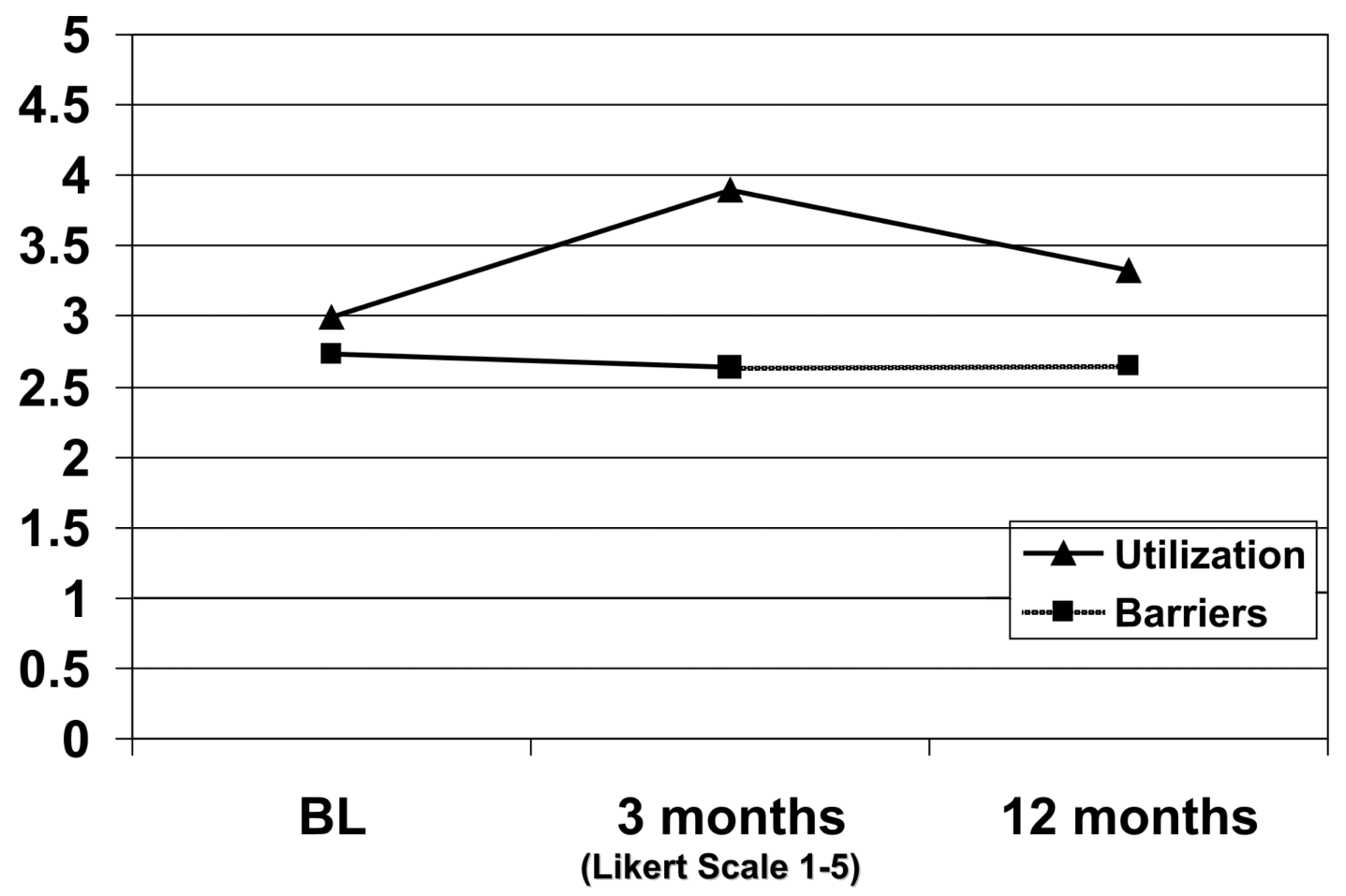

FIGURE 2.

Utilization and Perception of Barriers Over 12 Months 


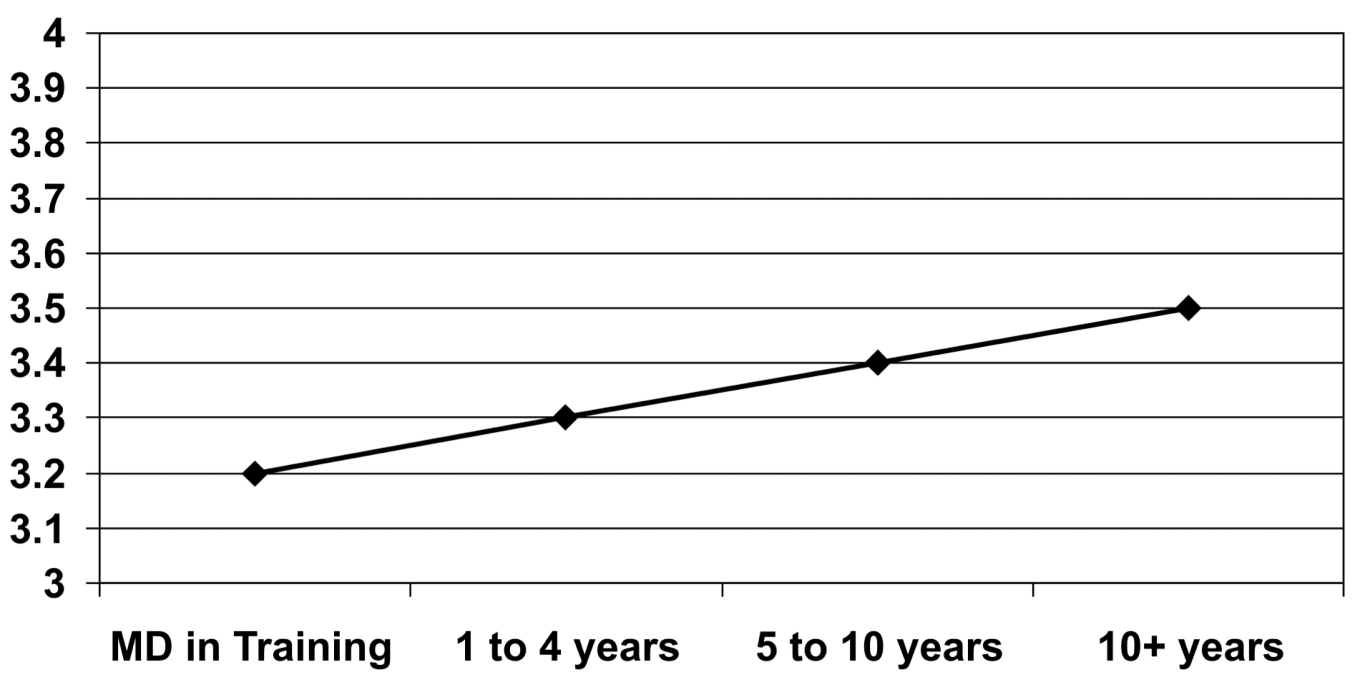

\section{Likert Scale 1 to 5}

FIGURE 3.

Likelihood of SBIRT Utilization Change with Years in Practice 
TABLE 1

Changes in Provider Beliefs and Practices from Baseline to One Year Post Exposure to a Screening, Brief Intervention and Referral to Treatment Curriculum (SBIRT)

\begin{tabular}{|l|c|l|l|}
\hline Characteristic & Baseline & $\mathbf{3}$ months & $\mathbf{1 2}$ months \\
\hline Confidence in ability to perform the elements of SBIRT & 3.75 & $\begin{array}{l}4.15 \\
\text { pre-post difference }=0.40 \\
\mathrm{p}<.001,95 \% \mathrm{CI}-.50,-.32\end{array}$ & $\begin{array}{l}4.06 \\
\text { pre-post difference }=0.31 \\
\mathrm{p}<.002,95 \% \mathrm{CI}-.41,-.21\end{array}$ \\
\hline Responsibility to provide SBIRT & 3.74 & $\begin{array}{l}4.01 \\
\text { pre-post difference }=0.25 \\
\mathrm{p}<.001,95 \% \mathrm{CI}-.33,-.17\end{array}$ & $\begin{array}{l}3.91 \\
\text { pre-post difference }=0.18 \\
\mathrm{p}<.04,95 \% \mathrm{CI}-.27,-.10\end{array}$ \\
\hline Barriers to Utilization of SBIRT & 2.73 & $\begin{array}{l}2.64 \\
\text { pre-post difference }=0.09 \\
\mathrm{p}<.004,95 \% \mathrm{CI}-.03,-.15\end{array}$ & $\begin{array}{l}2.65 \\
\text { pre-post differences }=.05 \\
\mathrm{p}=\mathrm{NS} ; 95 \% \mathrm{CI}-.02,13\end{array}$ \\
\hline Utilization of SBIRT & 2.99 & $\begin{array}{l}3.89 \\
\text { pre-post difference }=0.90 \\
\mathrm{p}<.001,95 \% \mathrm{CI}-.98,-.83\end{array}$ & $\begin{array}{l}3.32 \\
\text { pre-post difference }=0.37 \\
\mathrm{p}<.001,95 \% \mathrm{CI}-.44,-.30\end{array}$ \\
\hline
\end{tabular}

values represent composite domain mean scores, with a scale range 1 (least) to 5 (most) 
TABLE 2

Composite Mean Scores at Baseline and at 1 Year Follow-Up ${ }^{*}$ Comparison with Controlled Trial, $2002^{17}$

\begin{tabular}{|c|c|c|c|c|}
\hline & $\begin{array}{c}\text { D'Onofrio et al. Intervention Site } \\
\mathbf{n = 1 7}(\mathbf{1 0 0 \%} \mathbf{f} / \mathbf{u} \text { rate) }\end{array}$ & $\begin{array}{c}\text { \% change in means } \\
\text { pre/post }\end{array}$ & $\begin{array}{c}\text { NASD ED SBIRT Collaborative } \\
\mathbf{n = 4 0 1} \text { (72\% f/u rate) }\end{array}$ & $\begin{array}{c}\text { \% change in means } \\
\text { pre/post }\end{array}$ \\
\hline Confidence & $66.6 / 74.7$ & 12 & $75.0 / 81.2$ & 8 \\
\hline Responsibility & $72.6 / 72.3$ & $<1$ & $74.8 / 78.2$ & 5 \\
\hline Utilization & $48.4 / 54.8$ & 17 & $59.8 / 66.4$ & 19 \\
\hline
\end{tabular}

f/u=follow-up

NASD=National Alcohol Screening Day

$\mathrm{ED}=$ emergency Department

SBIRT=Screening, Brief Intervention and Referral to Treatment

* scores scaled to 0-100 